\title{
Everyone Loves Live Music: A Theory of Performance Institutions
}

\author{
Daniel Nordgård \\ Faculty of Fine Arts, University of Agder, Norway \\ Fabian Holt, Roskilde University, The University of Chicago Press, 2020, pp 347 \\ ISBN (Print) 9780226738543, 9780226738406
}

With his new book, Fabian Holt provides a critical assessment of current live music discourse and prospects for new theory in the field of live music research. As the book's sub-title suggests, focus is on performance institutions - the club and the festival, and an ambition to provide new theory that captures transformations in these institutions. Holt argues for broader academic perspectives on live performance institutions, more grounded in the humanities and less on business- and industry-research. Fabian Holt posits that performance culture's position in music studies has been uncritically viewed through industry lenses and proposes a sociological approach instead. The author further argues that the book provides an alternative concept for analysing and discussing live music, to the predominant discourses. In that sense, the book might be considered by some to be outside the realm of a journal in music business research. However, Holt's thorough and detailed descriptions of developments in the fields of rock clubs and festivals are valuable contributions to the research of music business, as are the analytical frameworks proposed in the book.

The book is structured through ten chapters, organised in three main parts. The first two chapters provide a theoretical framework for the following chapters to be read within. The second part - chapters three to five - focuses on the rock clubs in Europe and in New York. Chapters six to nine constitute part three of the book, which is dedicated to festivals and the summer season - and chapter ten is dedicated to a conclusion. The book is a valuable contribution to the research of music, or to students in search of broader frameworks to read, or research live music within.

Much of the book builds on thorough and rather detailed historic accounts of rock clubs, festivals and policy - or political developments in the respective regions and cities. And while these historic accounts are valuable (such as the New York clubs in chapter four, or the historic accounts of western festival growth in chapters seven and eight), it's not all clear to this reader how these accounts develop into new theory. It would appear that the purpose of the framework offered in the book is to assess music performance institutions against the backdrop of the history of the changing framework conditions and ownerships of clubs and festivals. Holt makes several points, arguing the central position of history in his analysis, such as in $\mathrm{p}$ 168: History is essential to this book's interest in denaturalizing live music and the conditions of performance culture in contemporary society, or the whole of chapter six. He also argues to broaden our debates and avoid limitations from 'industry-discourse'. Throughout the book, there's a continuous critique of the general live music discourse being excessively based on capitalistic measures and values. And although this might be true, the question becomes whether the alternative is equally limiting. Developments described in the book are closely linked to issues and developments described thoroughly in more 'industry-, or management-centred' literature - and could these perhaps be linked in some way? The division between what Holt seems to present as the ideal models for performance culture and corporate consumer culture, is difficult to fully determine. And it's not all clear how these divisions lead to new theory, beyond (rightfully) pointing out the need for including the humanities in academic discourse, and to view developments in longer historic lines.

One of the book's many good offers is the data built on Holt's experience as a field researcher and accounts from an extensive period of data gathering in Denmark, Europe and in the US. This alone provides a much-needed addition to the field of research and the empirical foundations usually provided in research on performance institutions - or the live music industry. Holt's data also provides important insights to the difficult work of the researcher, the difficulties of working at the crossroads of culture and big business and being dependent on business logics to correspond with academic freedom and scientific conduct. These accounts offer important detail to the field, to historic events and historic places, and some will certainly become a point of reference for future researchers. 